\title{
STEWARDSHIP: A Conceptual Imperative For Managerial Effectiveness In The Nigerian Health System
}

KEY WORDS: Stewardship, Managerial Imperative, Nigeria

\author{
All Correspondence to: \\ Dr. R. I. Ogbimi (PHD) \\ Institute of Public Administration \\ and Extension Services, \\ University of Benin, Benin-City \\ Edo State, Nigeria.
}

\begin{abstract}
Unacceptable health status indicators such as high infant and maternal mortality rates and low life expectancy have continued unabated inspite of government efforts to change it. This paper espouses the concept of stewardship as a selfless, ethical, cost effective and outcome oriented approach to governance. It is believed that through stewardship approach governments would improve the health status of their populations considerably. The paper implores not only government and health care managers but the Nigerian society also to imbibe the concept of stewardship to make the development of a result-oriented health system easy.
\end{abstract}

\section{INTRODUCTION}

From the first national development plan after Nigeria's independence till present, government has been making efforts to improve on the health status of Nigerians such as in health manpower development and building health infrastructural facilities. ${ }^{1}$

These efforts have not improved the health status of Nigerians to acceptable levels.

Infant and maternal mortality rates are unacceptable and preventable diseases continue to be major causes of morbidity and mortality. In line with World Health Organisation's ${ }^{2}$ initiative, this paper intends to espouse the concept of stewardship and implores all stakeholders in the health system to adopt it in order to attain the acceptable level of health status for Nigerian populations.

Stewardship is a concept in religious doctrine. Historically God mandated man to tend and keep 'the garden of Eden' which consists of God's creation (Genesis 2:15). The understanding here is that when entrusted with something of value such as population's health, there is an obligation not only to preserve but also to improve on it. ${ }^{3}$ The parable of the talents (Matthew 25:14-30); the state of Egypt entrusted to Joseph as steward and how he effectively managed the state to the satisfaction of all concerned in the holy scriptures were significations of stewardship. The value is given in trust to the 'agent' and the 'agent' preserves and builds trust by responsiveness to legitimate needs and expectations of the population that owns the value. Accordingly in employee grievance settlement procedure the services of stewards were employed for National Federation of Federal Employees in United States of America. ${ }^{4}$ Identifiable characteristics of these stewards were that they:

- $\quad$ are trained for the job of stewardship

- address problems before they arise

- apply justice and equity in their operations

- determine legitimacy of demands and

- labour to satisfy the ones for whom the value is held in trust.

Thus stewardship bears strong relationship with governance and administration by which institutions operate, focusing on the 'common good' or public interest.

The notion of stewardship has progressed from this ideological discourse to a more empirical one in which public health policy and its implementation focus on the health status and satisfaction of populations to improve them through stewardship function of a state.

\section{Definition of Key Terms}

A steward is a selfless servant who manages entrusted assets or values without owning them, anticipates future trends through informed predictions and devises overall plans.

The commitment principle in planning ${ }^{5}$ mandates the steward to make workable plans and be involved with monitoring and evaluating plan implementation to ensure the achievement of set goals. In this respect the following terms are hereunder defined:

Stewardship: This is a concept defined as an outcome oriented approach to governance by which entrusted national health is efficiently and ethically handled in the spirit of social justice and equity. The policy-making and regulation role of the federal ministry of health is crucial and transcends other levels of government especially in areas where constitutional autonomy could hinder effectiveness of plan implementation among the federating states (Stewardship in health). This is to ensure compliance to public health policy and regulation. Secondly effective management of the health system to improve populations health depends largely not only on workable public policies but also on attestable willingness to provide funds and other resources for the management of the health sector (Stewardship of health). Thirdly socio-political stability that favours stewardship is required to attract and coordinate the necessary inputs from other sectors for health systems development and function (Stewardship for health). Examples of other sectors are agriculture, water resources, transport and communications, nongovernmental organizations and international donor agencies. 
An enabling environment is required for stewardship. Political overlords at all levels of government and the ministries of health are expected to engineer not only managers in the health sector but society indoctrination for stewardship knowing that these categories of public functionaries often operate within the mind-set and traditions of society for which values are held in trust.

Conceptual imperative: This is a basic and required knowledge, mind-set or reasoning pattern.

Common interest: This is a selfless interest in service wherein the goal of attaining acceptable health status indicators is focused upon in national health policy.

Governance: In this paper means institutions and traditions by which authority and power in a country are exercised for public health.

Decision making: Means making policies, plans, objectives, rules and regulations, programme implementation strategies for public health.

The health system: The health system may be defined as the functionally interrelated and interacting sectors which affect individual and community health. The health system is not only the health sector but includes other sectors such as water resources, economic, agriculture and political sectors.

\section{Progress and Difficulties in Health Systems Development}

National development plans in health since post Nigerian independence had identified management problems as major contributions to unacceptable level of health sector development and performance. Examples of these management problems at the plan periods were insufficient health manpower (19621968), rural-urban and curative-preventive health resource mal-distribution, as well as $95 \%$ of ill-health and deaths in the country being caused by preventable health problems (1970-1974, 1975-1980, 1981-1985 and 1986-1991 plan periods). ${ }^{6-10}$ Managerial inefficiency such as fund misappropriation, poor personnel control and distribution, inadequate funding, unsuitable working conditions that result in brain drain were reported in subsequent development plans. Though these problems were identified as plaguing the health sector, the scarcity of health mangers as well as the need for them to receive an appropriate training were for the first time stressed in the fifth national development plan (1986-1991). ${ }^{11}$

As part of the measures to redress these problems, the ministry of health was restructured into at least eight departments headed by directors to reflect some key health service areas and to specially provide for the primary health care approach to health systems development. The chief executive position in health care institutions was made the exclusive preserve of medical doctors by decree 10 of 1985, an attempt to reduce medical brain drain and improve managerial quality. Private practice in the health sector was somewhat liberalized. Health care professionals were allowed to own health care institutions which was an attempt at health sector decentralization and improving population access to health services. Another cadre of health workers (the community health workers) was introduced into the health system from 1979 mainly to serve the rural population with qualified health workers.

Inspite of the foregoing measures, health sector problems such as poor funding, managerial inefficiency, high labour turnover among health care professionals and difficulty with considerably reducing preventable diseases and deaths have persisted. Therefore politicians and managers are being implored to imbibe the concept of stewardship and apply its approach to health systems development. The difficulties or dilemmas of stewardship can be surmounted but they must first be identified, such as:

- Disobedience of many public servants and politicians in Nigeria to agreed public service approaches have often influenced the discharge of responsibilities. Democracy is our approach to governance. Appreciation of the tenets of democracy such as populations right to health and safety is a fundamental requirement for effective stewardship in health. The role of the manager is crucial in the political decision-making process particularly in relating policy to implementation because ineffective implementation can waterdown an intended health policy outcome or drastically change it. ${ }^{12}$ Political, religious and socioeconomic realities could hinder the implementation of stewardship approach such as systems that permit self-serving groups to dominate the affairs of the state.

Regionalization such as autonomy of the federating states in Nigeria could potentially diminish the ability of federal government to design and implement the desired regulatory strategies in stewardship. This difficulty impinges on maldistribution of health resource in Nigeria. ${ }^{13}$

Traditional theories, beliefs, values and norms in public organizations could create inherent limitations on government ability to respond effectively to legitimate public needs and demands for health. If economic efficiency and cutting costs are the main interests in the health sector where majority of the populations are poor and handicapped, stewardship approach would be difficult to employ.

For stewardship to succeed as a model of health policy making, a clear and consistent strategic direction is required. Meanwhile from one political leadership to another, consistent strategic policy direction has been difficult.

Real change agents or organization development consultants that would be acceptable to health care personnel would take time to become available as they are needed for restructuring health care organizations 
and reorienting health care personnel. This may include influencing the thought patterns of political overlords in the health sector and for intersectoral cooperation in health.

Stewardship in health: The role of government Accountability means liability for the proper discharge of duties by subordinates. In democratic systems elected and appointed public officials are subordinate and accountable to the electorate for the proper discharge of their responsibilities. There is high demand for efficiency of service and responsiveness to populations health needs in Nigerian health system and in many other developing counties. Some may argue that the demand for economic efficiency in public service contravenes adequate health service to the poor and hence the larger proportion of the population receive either inadequate or no professional health care. The regulatory mechanisms in stewardship help to incorporate service efficiency and the advocacy approach to governance in which ethics, social equity and justice are important driving forces deriving from administrative and behavioural science schools of thought in management literature.

Ethics and social equity are basically matters of conscience. Political leaders and managers at all levels of government must attempt to shape the social conscience favourably, principally because they are accountable for the ethical ramifications of their action. ${ }^{12}$ Justice is based on laid down policies, standards, rules and regulations of supervisory organizations in health.

Government is responsible and accountable to society for public health. The structural arrangement for public health accountability can be visualized from elected political officials and appointed executives in federal, state and local governments to professional health care managers in ministries of health and other health care organizations as well as community leaders. The underlying principles are that first these stakeholders are bound by the law of the land and are obligated to use their power in good faith in public interest. Secondly no public official, high or low owns the government, his organization or his office. The government belongs to the public and the stakeholders role is that of a trustee not a proprietor in the use of his authority. ${ }^{14}$

There is a general consensus that state behavioural change is required for applying state authority that ensures responsive polices, equity in health resource management and for responding to public health needs. Accordingly the World Health Organization defines stewardship as effective trusteeship of national health. This means that stewardship responsibility is laid on the state as the agent for effective health care system in a country.

Inter-country comparisons of health status indicators primarily show that in similar circumstances or improved socio-economic conditions, better population health status can be achieved especially if stewardship approach is applied to realign state authority in the health system in the interest of achieving the goal of public health policy. It can be observed that neighboring developing countries like Benin and Ghana as well as distant China, over time (1997-2001) allocated higher percentage of their GDP to the health sector when compared with Nigeria (Table 1).

Table 1: Health Expenditure and life expectancy of selected countries.

\begin{tabular}{|l|ll|ll|}
\hline Country & \multicolumn{2}{|c|}{$\begin{array}{l}\text { Total Expenditure on } \\
\text { health as percent of } \\
\text { GDP }\end{array}$} & \multicolumn{2}{|c|}{$\begin{array}{l}\text { Life Expectancy at } \\
\text { Birth (Years) } \\
\text { (Both Sexes) }\end{array}$} \\
\hline Nigeria & $\mathbf{1 9 9 7}$ & $\mathbf{2 0 0 1}$ & $\mathbf{1 9 9 3}$ & $\mathbf{2 0 0 2}$ \\
\hline Ghana & 4.8 & 3.4 & 53 & 48.8 \\
\hline Benin & 3.7 & 4.7 & 56 & 57.6 \\
\hline China & 4.6 & 4.4 & 46 & 51.2 \\
\hline
\end{tabular}

Source: World Health Report 2004. Changing History. P. 132-136

In the same vein, although preventable infectious diseases such as HIV/AIDS, tuberculosis and malaria ravage many developing countries, Nigeria unlike other countries on the Table has decreasing years of life expectancy at birth from 1993 to $2002 .{ }^{15} \mathrm{Life}$ expectancy of 71.2 years for China in 2002 shows the possibility of governments in developing countries to improve the longevity of their populations.

Diseases such as trypanosomiasis and leishmaniasis termed 'poor peoples diseases. ${ }^{16}$ identified in southsouth Nigeria and some northern states indicate that the concept of stewardship in governance is needed to facilitate health awareness and access to health care facilities for 'disadvantaged populations' such as the young, aged, illiterate and the physically challenged. Stewardship is outcome oriented and governments would easily assess their performance with improved populations health status indicators.

Intersectoral cooperation and collaboration for public health is fostered by government through effective public policies and monitoring. For instance, insecurity of lives and property, poor coverage of populations with potable water and poor funding of the health sector would result in higher morbidity and mortality, increasing utilization of and cost to the health sector with the outcome of decreasing life expectancy at birth. In operational terms, stewardship function of government may be observed when:

- Fund allocation to the health sector is in accordance to WHO recommendation

- Populations are protected from unqualified health care practitioners

- Health care services are accessible to all

- There are effective national policies and programmes that considerably reduce or eradicate preventable infectious diseases already stated above 
- Labour turn-over in the health sector is considerably reduced.

- There are effective public health care policies, monitoring and evaluation of policy implementation to ensure intended outcome.

- Accurate statistics on health are available to the ministries of health yearly.

- Infant and maternal mortality rates have been reduced to tolerable levels.

- Life expectancy of Nigerians have considerably increased at least to that of China (Table1).

\section{Conclusion}

Stewardship is a concept of selfless and result-oriented governance which incorporates economic efficiency with ethics, equity and justice for public service. It has emerged as the best approach to unite multiethnic diversity within a democratic dispensation. Its tenets rest mainly on equitable resource distribution in the spirit of social justice and equity. Stewardship as a resultoriented approach to health systems development focuses and brings to acceptable levels the health status indicators of populations. Developing countries like Nigeria are especially implored to adopt this concept for health system development.

\section{Recommendations}

The following recommendations are hereunder proffered:

- The health sector should be reorganized to have considerable autonomy from political overlords so that funds could be allocated directly to the health sector and resource distribution will cut across political and regional barriers. Integrated zonal health care system is suggested, such as that in New Zealand. ${ }^{17}$ By this health service is depoliticized by establishing a non-political organisation empowered to acquire and distribute health care resources across political and geographical boundaries. ${ }^{13}$

- For effective monitoring and evaluation of work in the health sector, supervisory facilities such as transport should be made available especially for the remote and rural areas.

- Ministry of health should make available yearly accurate health statistics for the country.

- Government should improve civil obedience to the state through responsible leadership. By this, management responsibilities in meeting stewardship goals become easier.

- Government should make and enforce laws on health considerations in the operations of other sectors in the health system such as in building construction, transport, environment and family size determination.

- Stewardship approach to health systems development should be adopted for public service because it suits multiethnic societies like Nigeria as it is rooted in democratic ideals of society as a whole which is based on consensus that permits acceptable interrelationships among the federating states.

- Government should indoctrinate society with stewardship concept to enable public health managers develop the sense of direction, to build and restore trust hitherto found wanting in public service employees in Nigeria.

- Government should considerably reduce fund and other resource diversion among health care managers.

- Intersectoral cooperation and coordination should be vigorously pursued for public health.

- Government should summon the cooperation of health workers in determining and creating suitable work conditions.

\section{References}

1. Nigeria. Federal Ministry of Health Draft National health Policy, Abuja. 2004:10-24

2. World Health Organization Health Status Indicators, Word Health report. Geneva, 2000:62-72

3. Richard, B; Saltman and Odile Ferroussier-Davis, The concept of stewardship in health policy Bulletin of the World Health Organization 2000; 78 (6) 715-865.

4. Nigro, F.A; Nigro, L.G. The New Public Personnel Administration. F.E. Peacock Publishers, Inc. Illinois. 1981; 392-393

5. Koontz, H; O’Donnell, C; Weihrich, H; Management. McGraw-Hill Co. London. 1980:297

6. Nigeria. Federal Ministry of Information. The First National development Plan, 1962-1968, Lagos. 1962:10

7. Nigeria. Federal Ministry of Information Second National Development Plan, 1970-1974 Lagos, 1970:247-248

8. Nigeria. Federal Ministry of Economic Development. The Third National Development Plan 1975-1980, Lagos, 1975, 263-265

9. Nigeria. Federal Ministry of Economic Development. The Fourth National

Development Plan 1981-1985, Lagos, 1981; 275-281

10. Nigeria. Federal Ministry of Health National Health Policy and strategy to achieve health for all. The Fifth National Development Plan 19861991, Lagos. 1986, 3-6.

11. Ogbimi, R.I. Factors influencing the distribution of nurses and community health workers in 
selected Local Government Areas in Oyo and Bendel States. PhD Thesis (Unpublished) submitted to Department of Preventive and Social Medicine University of Ibadan 1992:38-43

12. Ogbimi, R.I. Health considerations in rural development. Benin Journal of Educational Studies. 2004;18(1\&2) 163-175

13. Ogbimi, R.I. Utilization of University Teaching Hospitals in the Southern health zone of Nigeria. Mary Slessor Journal of Medicine. 2006; 6(1) 1325

14. Murphy, T. P. Contemporary Public Administration. F.E. Peacock Publisher Inc. Illinois, 1981; 480-492
15. World Health Organization (2004) Health Status indicators. Word health report 2004, Changing history. Geneva, 2004: 132-136

16. Business Day. Giving attention to poor peoples diseases. Tues. Oct. 24 Lagos, 2006 5, 211, 16, Editorial.

17. Malcolm, L. A., new primary health care delivery model. Decentralized accountable leadership. Key ingredients in real system reform. Australian International Health Institute. Global health reform. 2000:1, 6-7 